\title{
Modeling the Effect of Bank Specific Factors on Financial Performance of Commercial Banks in Nigeria: Panel Data Regression Approach
}

\author{
*Y. Yakubu and S. M. Egopija \\ Department of Statistics, School of Physical Sciences, Federal University of Technology, Minna, Niger State, Nigeria \\ [ ${ }^{\star}$ Corresponding Author: E-mail: yisa.yakubu@futminna.edu.ng]
}

\begin{abstract}
Periodic checking and evaluation of financial performance of the banking sector is a way of sustaining the development of a nation's economy. The key indicators of the banks' financial performance are their return on assets (ROA) and return on equity (ROE). A bank's financial performance is affected by some specific factors like capital adequacy ratio (CAR), credit risk (CRISK), management quality, liquidity ratio (LIQ.RAT.) and bank size. This work first compares average financial performance of some sampled commercial banks in Nigeria (UBA, GTB, ZENITH, FIRST, and ACCESS banks) based on the key indicators and the bank specific factors. It then models the effect of these factors on the overall financial performance of the sampled banks using panel data regression approach. The results showed that the GTB had the highest average ROA, ROE and CAR throughout the period under review while Zenith bank was the best in terms of credit risk, management quality and liquidity ratio. The fitted ROA model accounted for $83 \%$ of the total variability in the data and revealed that CAR, CRISK, and LIQ.RAT were significant at both $1 \%$ and $5 \%$ levels while the ROE model accounted for $69 \%$ and revealed that CRISK and LIQ.RAT were significant.
\end{abstract}

Keywords: Financial Performance, Commercial Banks, Evaluation, Panel Data, Economy.

\section{INTRODUCTION}

Commercial banks play crucial role in a nation's economic growth and industrialization through continuous channeling of funds from depositors to investors, and in the process gaining from the spread of the different interests charged. Banks are important component of the financial sector of any economy because of their role as financial intermediaries that helps facilitate capital to promote productivity and thereby enhancing growth and development in the economy (Misra and Aspal, 2013). Beyond the intermediation function, the financial performance of banks has critical implications for economic growth of countries. Good financial performance rewards the shareholders for their investment. This in turn encourages additional investment and brings about economic growth. On the other hand, poor banking performance can lead to banking failure and crisis which have negative repercussions on the economic growth.

The financial performance of a bank is its ability to make use of available resources to boost shareholders' wealth, and at the same time, strengthen its capital base to ensure future survival and profitability. Evaluation of financial performance of the banking sector is an effective measure and indicator to check the soundness of economic activities of a nation. This is so because the banking sector's performance is perceived as the replica of economic activities of the nation. The stage of development of the banking industry is a good reflection of the development of the economy (Misra and Aspal, 2013). Periodic evaluation will enable the shareholders to assess which banks could be suitable for financial investment. This will also enable the banks to determine the efficacy and long term viability of their management decisions or goals so that they can alter the course and make changes whenever it is appropriate (European Central Bank (ECB), 2010). First of all, a bank must be able to produce incomes to remain in operation. Furthermore, it should be effective, that is, it should be able to create revenue from the given assets and make profits. Thirdly, it should be able to regulate its earnings to overcome the numerous risks associated, such as credit risk, and finally it should be able to improve its results through the approach it functions. 
A more organized study of bank performance started in the late 1980's (Olweny and Shipho, 2011) with the application of Market Power (MP) and Efficiency Structure (ES) theories (Athanasoglou et al., 2008.) Balanced portfolio theory added additional dimension into the study of bank performance (Olweny and Shipho, 2011). The theory states that the portfolio composition of the bank, its profit and the return to the shareholders is the result of the decisions made by the management and the overall policy decisions. From the above theories, it is possible to conclude that bank performance is influenced by both internal and external factors. According to Athanasoglou et al (2008) the internal factors include bank size, capital adequacy, management efficiency and risk management capacity. The same scholars contend that the major external factors that influence bank performance are macroeconomic variables such as interest rate, inflation, economic growth and other factors like ownership.

\section{MATERIALS AND METHODS}

The population of this study comprises of all the commercial banks in Nigeria out of which five banks were randomly sampled by means of a random number Table. The sampled banks include Zenith Bank, Guarantee Trust Bank (GTB), United Bank for Africa (UBA), Access Bank and First Bank. Secondary data on each of the two dependent variables (ROA) and $(\mathrm{ROE})$ and the five independent variables were generated from the published and audited annual financial report of each of the banks for the period $2010-2017$. Two estimation methods were used in this work, which included the pooled and the fixed effects models.

\section{The pooled Model}

The pooled model does not differ from the common regression equation. It regards each observation as unrelated to the others ignoring panels and time. No panel information is used. A pooled model can be expressed as:

$y_{i t}=\beta_{0}+\beta_{1} X_{1, i t}+\beta_{2} X_{2, i t}+\cdots+$ $\beta_{k} X_{k, i t}+\epsilon_{i t} \quad(1)$
A pooled model is used under the assumption that the individuals behave in the same way, where there is homoscedasticity and no autocorrelation. Only then OLS can be used for obtaining efficient estimates. The assumptions for the pooled model are the same as for the simple regression model as described by Greene (2012).

\section{The Fixed effects Model}

One of the advantages of using panel data as mention in Section 1 above is that models like the fixed effects model can deal with the unobserved heterogeneity. The fixed effects model for factors can be expressed as

$y_{i t}=\alpha_{i}+\beta_{1} X_{1, i t}+\beta_{2} X_{2, i t}+\cdots+$

$\beta_{k} X_{k, i t}+\epsilon_{i t}$

Where $y_{i t}$ denotes the observed outcome of entity $i$ at time $t, X_{i t}$ is the $(1 \mathrm{x} K)$ vector of covariates of this entity measured contemporaneously, and $\beta$ is the corresponding $(K \times 1)$ vector of parameters to be estimated. The $\alpha_{i}$ are stable, entity-specific characteristics. That is, $\alpha_{i}$ are unobserved effects capturing time-constant individual heterogeneity. $\epsilon_{i t}$ is an idiosyncratic error that varies across subjects and over time. There is no constant term in the fixed effects model. Instead of the constant term $\beta_{0}$ in the pooled model (1) above, we have an individual-specific component $\alpha_{i}$ that determines a unique intercept for each individual. However, the slopes (the $\beta$ parameters) are the same for all individuals. Two methods are available for computing the estimates of the fixed effects model (Josef and Volker, 2015), which include the within-groups method and least squares dummy variable method (LSDV). The two methods yield equivalent results. However, the technique of including a dummy variable for each variable (that is, the second method) is feasible when the number of individuals $N$ is small. When the number of individuals is large, the within-groups method is the best because there will be too many dummy variables.

\section{The within-group method}

Given the fixed effects model in (2) above, for the within-group method when the sample size 
is large, first, one has to compute the means of all observed variables within individuals across time as follows.

$\bar{y}_{i .}=\frac{1}{T} \sum_{t=1}^{T} y_{i t} ; \quad \bar{x}_{l, i .}=\frac{1}{T} \sum_{t=1}^{T} x_{l, i t}$, $l=1, \ldots, K$

Equation (2) then takes the form

$\bar{y}_{i .}=\alpha_{i}+\beta_{1} \bar{x}_{1, i .}+\beta_{2} \bar{x}_{2, i .}+\cdots+$ $\beta_{k} \bar{x}_{k, i .}+\bar{\epsilon}_{i \text {. }}$

The term $\bar{\epsilon}_{i}$ is assumed to be 0 . Also, since $\alpha_{i}$ is time-invariant, its mean across time would stay as the original value for each individual. Next, equation (3) is subtracted from equation (2) as

$y_{i t}-\bar{y}_{i .}=\beta_{1}\left(X_{1, i t}-\bar{x}_{1, i}\right)+$

$\beta_{2}\left(X_{2, i t}-\bar{x}_{2, i .}\right)+\cdots+\beta_{k}\left(X_{k, i t}-\right.$

$\left.\bar{x}_{k, i .}\right)+\left(\epsilon_{i t}-\bar{\epsilon}_{i .}\right)$

By this subtraction, the individual specific component disappears. Also if a constant term had been used, it would have also disappeared. Let $\tilde{y}_{i t}=y_{i t}-\bar{y}_{i .}, \tilde{X}_{l, i t}=X_{l, i t}-\bar{x}_{l, i .}$, for $l=1, \ldots, K$ and $\tilde{\epsilon}_{i t}=\epsilon_{i t}-\bar{\epsilon}_{i .}$, then equation (4) can be written as $\tilde{y}_{i t}=\beta_{1} \tilde{X}_{1, i t}+\beta_{2} \tilde{X}_{2, i t}+\cdots+\beta_{k} \tilde{X}_{k, i t}+$ $\tilde{\epsilon}_{i t}$

The parameters and the individual-specific component can then be computed using the formulas:

$\hat{\beta}_{i}=\frac{\sum \sum \tilde{X}_{l, i t} \tilde{y}_{i t}}{\sum \sum \tilde{X}_{l, i t}^{2}} ; \hat{\alpha}_{i}=\bar{y}_{i .}-\hat{\beta}_{1} \bar{X}_{1, i .}-$

$\hat{\beta}_{2} \bar{X}_{2, i .}-\cdots-\hat{\beta}_{k} \bar{X}_{k, i}$.

These estimates are consistent.

\section{The Fixed Effects Least-Squares Dummy Variable Model (LSDV)}

Now, since this work considers five commercial banks (where $\mathrm{N}$ is not too large) for eight time periods, the LSDV is fitted to the collected data sets using ROA and ROE as the dependent variables. For our data with five banks, the fixed effects model with dummy variables, where intercepts $\alpha_{i}$ are different for different banks but each individual intercept does not vary over time is:

$$
\begin{aligned}
& y_{i t}=\alpha_{0}+\alpha_{1} D_{1}+\alpha_{2} D_{2}+\alpha_{3} D_{3}+ \\
& \alpha_{4} D_{4}+\beta_{1} X_{1, i t}+\beta_{2} X_{2, i t}+\beta_{3} X_{3, i t}+ \\
& \beta_{4} X_{4, i t}+\beta_{5} X_{5, i t}+\epsilon_{i t}
\end{aligned}
$$

Where $D_{k}$ denotes the $k^{\text {th }}$ bank, $k=1, \ldots, 5$, (Zenith, First, UBA, GTB and ACCESS), $X$ denotes cash adequacy ratio(CAR), credit risk, management, liquidity ratio, and size, respectively, $i$ stands for the $i^{\text {th }}$ bank, $i=$ $1, \ldots, 5$ and $t$ stands for the $t^{t h}$ time period $(t=2010, \ldots, 2017)$. Thus the individual effect is picked up by the dummy variable $D_{m i}$ where $m=n-1$ and the dummy variables are defined as

$D_{1 i}= \begin{cases}1, \quad i=1 \\ 0, \text { otherwise }\end{cases}$

$D_{2 i}=\left\{\begin{array}{l}1, \quad i=2 \\ 0, \text { otherwise }\end{array}\right.$

$D_{3 i}=\left\{\begin{array}{l}1, \quad i=3 \\ 0, \text { otherwise }\end{array}\right.$

$D_{4 i}=\left\{\begin{array}{l}1, \quad i=4 \\ 0, \text { otherwise }\end{array}\right.$

\section{RESULTS AND DISCUSSION}

\section{Average Financial Performance of Commercial Banks in Nigeria}

Table 1 presents the average financial performance of commercial banks in Nigeria as expressed by ROA and ROE for the year 2010 to 2017. As can be observed from the Table 1, the average ROA and ROE for the sector as a whole was 2.26 and 15.85 respectively. Compared to other countries bank performances as expressed by theabove ratios, the Nigerian commercial banks' performance is average. This is consistent with the findings of Flamini et al. (2009), which states that the average ROA in Sub-Saharan Africa, (SSA) was about $2 \%$. Thus, the average ROA of Nigerian banks is about average of the SSA.

Table 1. Eight years average Financial Performance of Commercial Banks in Nigeria

\begin{tabular}{lll}
\hline Indicators & ROA & ROE \\
\hline Mean Score & 2.26 & 15.85 \\
\hline
\end{tabular}


Overall Financial Performance

Summary of average financial performance based on ROA and ROE (2010 - 2017)

Figure 1 gives the overall mean return on assets achieved by the sampled commercial banks in Nigeria for the period 2010 to 2017. The findings show that the mean ROA for the commercial banks remains the same at 1.61 in 2010 and 2011 and then increased steadily from 2011 to 2012, which is the highest with a value of 3.23 . It then continued to decrease from 2012 to 2014 and then increased slowly to an average of 2.26 in 2015, then slowly decreased to 2.23 in 2016 and then to 2.49 in 2017. This is slightly different from the findings of Paul and Yazidu (2015), which observed a general trend of a decreasing banks' performance in Ghana as indicated both average $R O E$ and $R O A$.

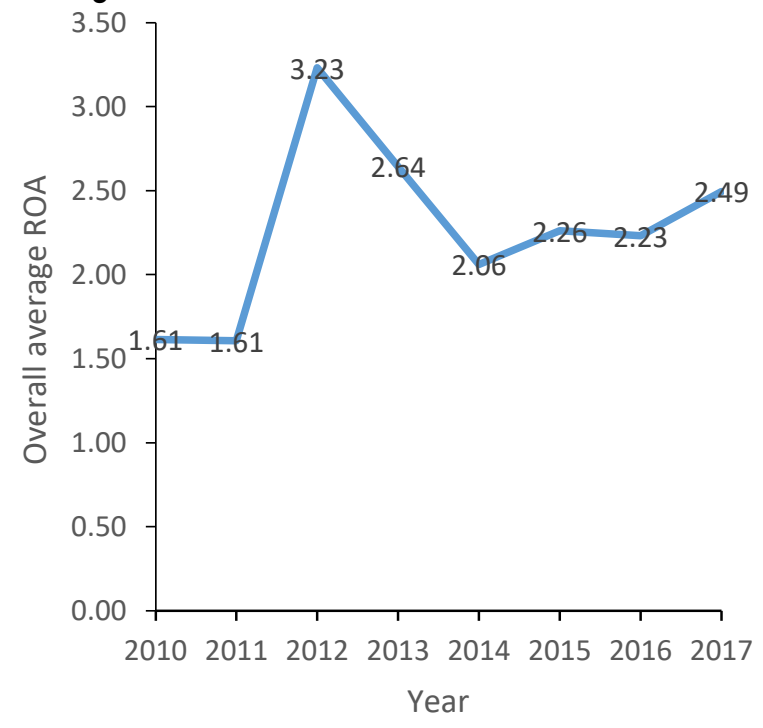

Figure 1: Overall mean ROA

Figure 2 shows the overall mean return on equity realized by the banking industry in Nigeria from 2010 to 2017. In 2010 the banks achieved an average ROE of 8.94 followed by an increase to 12.02 in 2011 and another sharp increase to 21.96 in 2012, which is the highest. ROE then continued to decrease slowly to an average of 14.90 in 2016 and then slightly increased to an average of 16.32 in 2017.

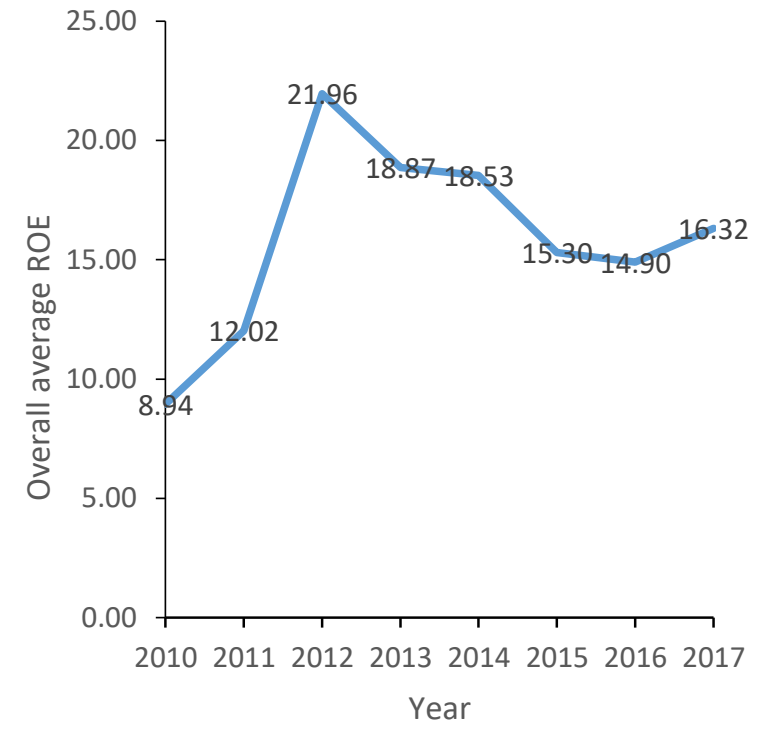

Figure 2: Overall mean ROE

Comparison of Banks based on key indicators and specific factors (2010 - 2017) Figures 3 and 4 revealed that GTB has the highest mean ROA of about 4.14 and ROE of about 25.23 for the period under review, indicating that this was the most efficient bank in terms of resources management as it made the highest profit with the money invested by its shareholders. This was followed by the ZENITH bank and then the ACCESS while FIRST bank came last in the two figures.

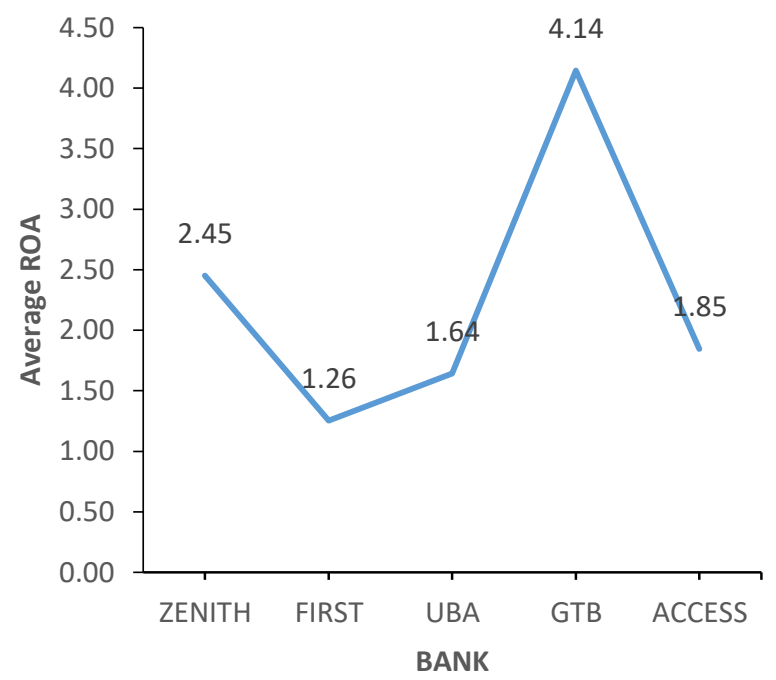

Figure 3: Average ROA 


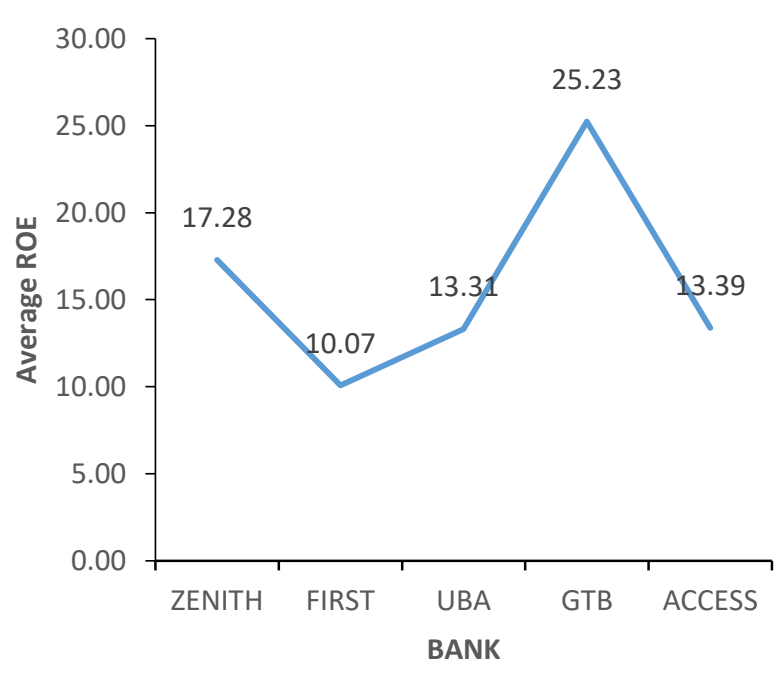

Figure 4: Average ROE

Figure 5 shows that GTB had the highest mean CAR, indicating that the bank had abundant capital to manage any shock to the balance sheet. Muhammad and Irfan (2011) also observed a high CAR for Islamic banks in Pakistan during the period of $2005-2009$. Figure 6 shows that, with the exception of ZENITH bank, the mean credit risk achieved by all other commercial banks were not significantly different and GTB had the highest level of credit risk.

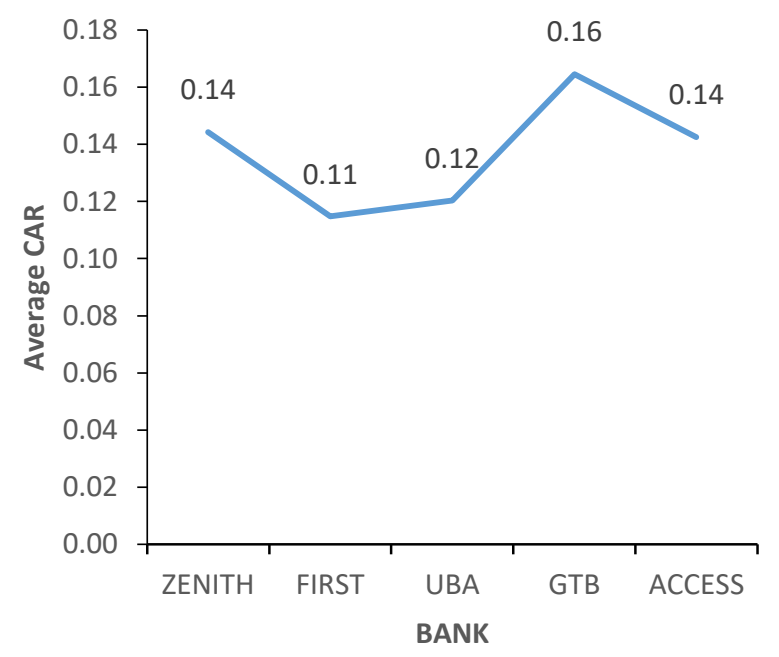

Figure 5: Average CAR

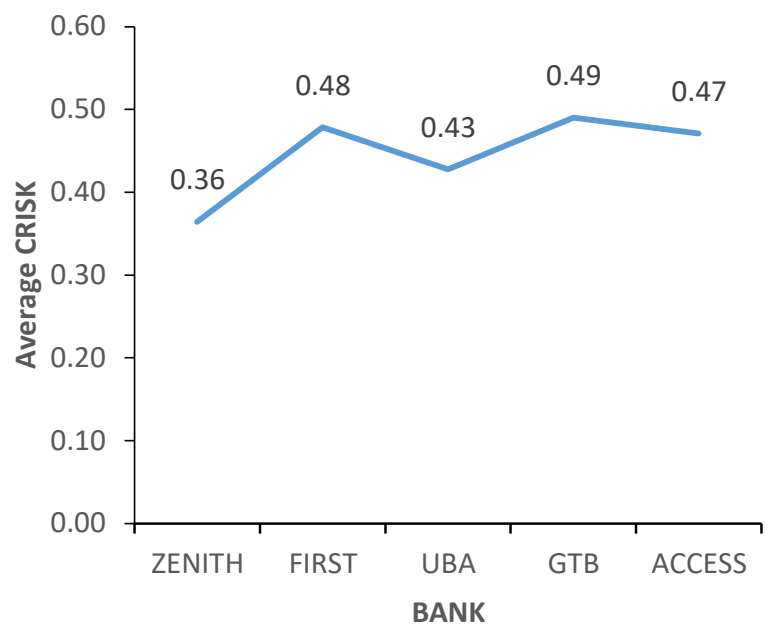

Figure 6: Average CRISK

Figure 7 revealed that ZENITH bank had the lowest mean operational ratio of $3.9 \%$, followed by ACCESS bank with a mean operational ratio of $4.1 \%$. GTB had a mean operational ratio of $4.2 \%$, FIRST bank had $4.5 \%$ while UBA recorded the highest mean operational expenses of $5.5 \%$. These results indicate that ZENITH bank has the highest operational efficiency while UBA has the lowest. Figure 8 reveals that UBA had the lowest average loan to assets ratio of $49.6 \%$ for the period under review, indicating that nearly $50 \%$ of the UBA assets were financed through debt during that period. This average indicates that UBA was in a better position with lower risk than the other commercial banks during the period under consideration. Figure 9 gives the mean bank size with respect to the sampled banks. We expect a positive relationship between size and profitability based on the view that a larger size should allow the bank to obtain economies of scale. 


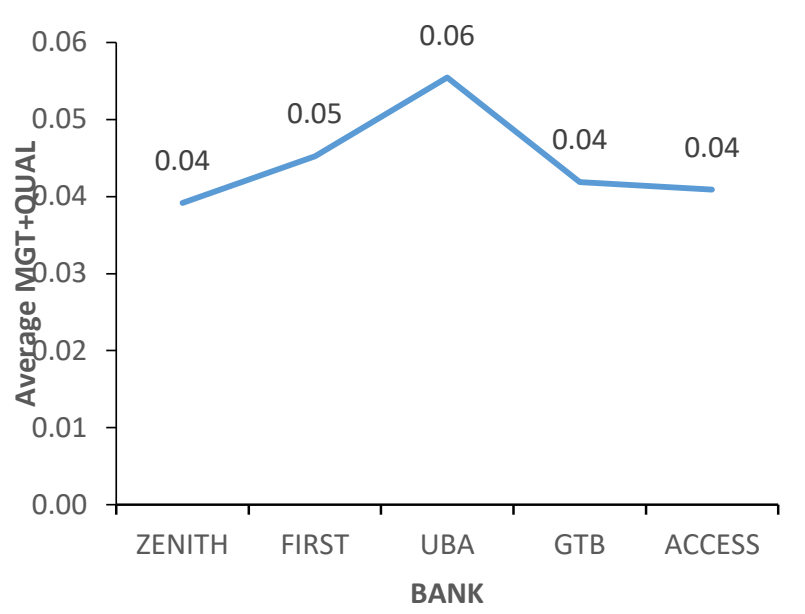

Figure 7: Average MGT Quality

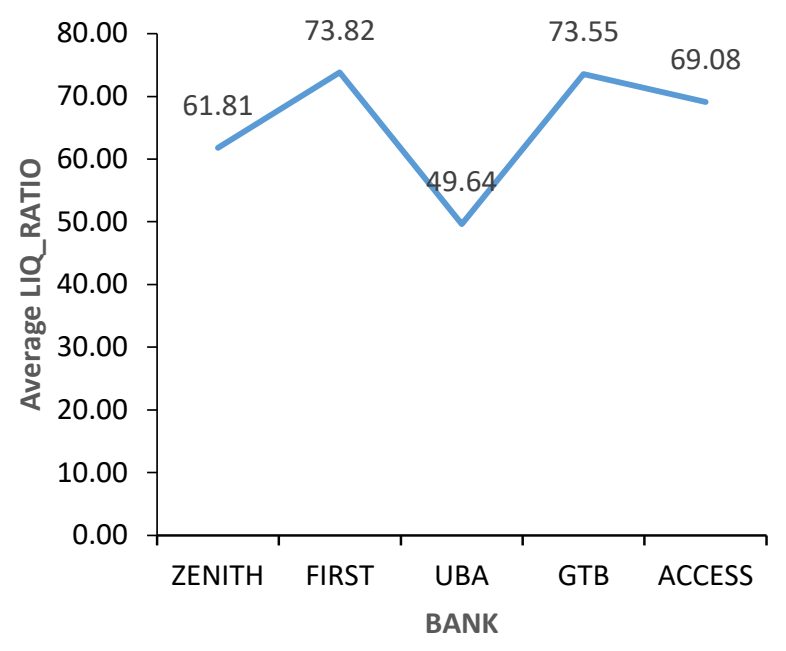

Figure 8: Average Liquidity Ratio

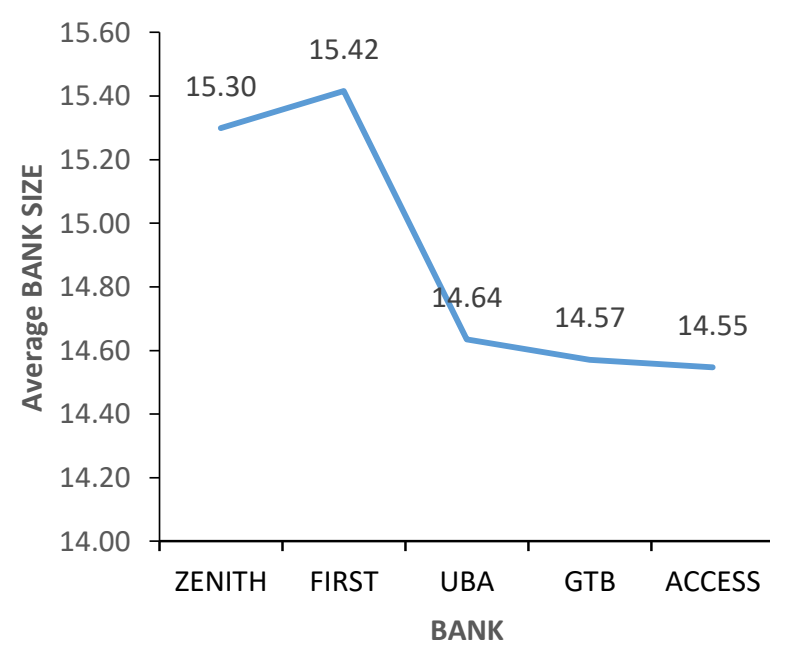

Figure 9: Average Bank Size

\section{The Fixed Effect LSDV Regression Models}

This section presents the relationship between the identified bank specific factors and the bank performance as expressed by ROA and ROE. Given the fixed effects LSDV model in equation (6), the fitted fixed effects model estimates for ROA and ROE as dependent variables are presented in Table 2. Each bank $i$ has $T$ observations and there are $i=1, \ldots, 5$ banks. Using LSDV technique, we introduce dummy variables so as to isolate individual bank specific effect in the fitted regression model. Therefore ACCESS bank has been set aside here as the reference category.

From the ROA model estimates in table 2, it was observed that each of the factors - capital adequacy ratio, credit risk and liquidity ratio, positively influence the financial performance of the banks as indicated by their highly significant effects with $p$-values of $0.024,0.003$ and 0.006 , respectively. The Table also shows that bank size was slightly significant with a $p$-value of 0.058. The fitted model (Equation 7) showed that for a given bank, as CAR changes across time by one unit, ROA increases by 13.88 units and as credit risk changes across time by one unit, ROA increases by 5.22 units. This is consistent with the findings of Vincent and Gemechu (2013), which observed a highly significant capital adequacy ratio in their study on financial performance of commercial banks in Kenya. However, the MGT factor has a negative and insignificant effect on the ROA for each of the banks sampled. The liquidity ratio also had a negative but significant effect on the ROA for each bank. The fitted model shows that as this variable changes across time by one unit for a given bank, ROA decreases by only 0.0423 units. The bank size has a positive and slightly significant effect on each bank's ROA as the model shows that a one unit change in bank size across time caused an increase of 0.642 units in ROA for any given bank.

From the ROE model estimates in Table 2, each of the capital adequacy ratio and MGT was observed to have a negative and insignificant effect on the bank's ROE while 
bank size has a positive but insignificant effect on the ROE of each of the sampled banks. The only factors with significant effects on ROE were the credit risk, which has a highly significant effect at both $1 \%$ and $5 \%$ significance levels, and liquidity ratio, which has a negative effect on ROE and is only significant at $5 \%$ level. This is also consistent with the findings of Vincent and Gemechu (2013). The fitted model (Equation 8) shows that for a given bank, as CAR changes across time by one unit, ROE decreases by 9.9 units while as credit risk changes across time by one unit for a given bank, ROE increases by 42.9 units. This is not surprising because loans and advances formed the major source of profit (interest) earned by banks. The model also shows that as MGT changes across time by one unit, ROE decreases by a huge amount of 124.9 units for a given bank while as liquidity ratio changes across time by one unit for a given bank, ROE decreases by only 0.263 units. However, a one unit change in bank size across time caused an increase of 3.24 units in ROE for any given bank, indicating that bank size plays an important role in determining the profitability of the bank using ROE as profitability measure.

This result is consistent with the findings of Siddiqqui and Shoaib (2011), which concluded that size of the bank plays an important role in determining the profitability of the bank using ROE as profitability measure. The fitted LSDV regression equations for the two dependent variables (ROA and ROE) are given in equations (7) and (8) as:

$$
\begin{gathered}
R O A_{i t}=-8.37+0.317 Z_{E N I T H_{B A N K}-} \\
0.533 F I R S T_{B A N K}-0.319 U B A+2.08 G T B+ \\
13.88 C A R+5.22 C R I S K-15.7 M G T- \\
0.0423 L I Q_{R A T}+0.642 B A N K_{-} S I Z E(7) \\
R O E_{i t}=-29.2+3.92 Z E N I T H_{B A N K}- \\
4.92 F I R S T_{B A N K}-2.02 U B A+12.47 G T B- \\
\text { 9.9CAR+42.9CRISK-124.9MGT- } \\
\text { 0.263LIQ } Q_{R A T}+3.24 B A N K \_S I Z E
\end{gathered}
$$

(8)

Table 2: Fixed Effects LSDV Model Estimates with ROA and ROE as the dependent variables

\begin{tabular}{lcccccc}
\hline \multicolumn{3}{c}{ MODEL1 (ROA) } & \multicolumn{3}{c}{ MODEL2 (ROE) } \\
\hline \multicolumn{1}{c}{ Term } & Coef & T-Value & P-value & Coef & T-Value & P-value \\
\hline CONST & -8.37 & -1.64 & 0.112 & -29.2 & -0.76 & 0.455 \\
ZENITH & 0.317 & 0.74 & $0.464^{\text {ns }}$ & 3.92 & 1.22 & $0.233^{\text {ns }}$ \\
FIRST & -0.533 & -1.35 & $0.187^{\text {ns }}$ & -4.92 & -1.65 & $0.109^{\text {ns }}$ \\
UBA & -0.319 & -0.68 & $0.502^{\text {ns }}$ & -2.02 & -0.57 & $0.573^{\text {ns }}$ \\
GTB & 2.08 & 6.31 & $0.000^{* *}$ & 12.47 & 5.01 & $0.000^{* *}$ \\
CAR & 13.88 & 2.37 & $0.024^{*}$ & -9.9 & -0.22 & $0.824^{\text {ns }}$ \\
CRISK & 5.22 & 3.19 & $0.003^{* *}$ & 42.9 & 3.48 & $0.002^{* *}$ \\
MGT & -15.7 & -1.35 & $0.187^{\text {ns }}$ & -124.9 & -1.42 & $0.165^{\text {ns }}$ \\
LIQ_RAT & -0.0423 & -2.95 & $0.006^{* *}$ & -0.263 & -2.43 & $0.021^{*}$ \\
BANK_SIZE & 0.642 & 1.97 & $0.058^{*}$ & 3.24 & 1.31 & 0.199 ns \\
R-SQUARE & $83.12 \%$ & & & $69.21 \%$ & & \\
R-SQRADJ & $78.05 \%$ & & & $59.97 \%$ & & \\
\hline
\end{tabular}

Note: The figures in parentheses are t-Statistics; * Statistically significant at $5 \%$ level only, ${ }^{*}$ Statistically significant at both $1 \%$ and $5 \%$ levels; $\mathbf{n s}=$ statistically not significant. 


\section{CONCLUSION}

This study examines the impact of bank specific factors on financial performance of commercial banks in Nigeria. Returns on asset and return on equity were taken as dependent variables while capital adequacy ratio, credit risk, management efficiency, liquidity ratio and bank size were taken as independent variables. The results from the plotted graphs revealed that the commercial banks under review exhibited different average achievements for each of the specific factors considered. Guarantee Trust Bank was the most efficient bank in terms of resources management as it has the highest mean ROA and mean ROE. The studyalso revealed that the two fitted LSDV models accounted for a significant proportion of variability in the ROA and ROE data. This indicates that these dependent variables were strongly influenced by these bank specific factors.

\section{REFERENCE}

Athanasoglou, P., Brissimis, S., and Delis, M. (2008). Bank-specific, industry-specific and macroeconomic determinants of bank profitability. Journal of International Financial Markets, Institutions and Money, 18(2):121 -136.

European Central Bank (2010) Annual Report.

Flamini, C., Valentina C., McDonald, G., Liliana, S. (2009). The Determinants of Commercial Bank Profitability in SubSaharan Africa. IMF Working Paper No. 09/15. International Monetary Fund, Washington, DC, USA. pp 1-32.

Greene, W. H. (2012). Econometric Analysis. 7th Edition, Prentice Hall, Upper Saddle River, New Jersey 07458. pp 1-828. ISBN 0-13-066189-9.
Josef B. and Volker L. (2015). Fixed-effects Panel Regression. The Sage Handbook of Regression Analysis and Causal Inference. Sage Reference, London, pp 326-357.

Muhammad Jaffar and Irfan Manarvi (2011). Performance comparison of Islamic and Conventional banks in Pakistan. Global Journal of Management and Business Research, 11(1). Global Journals Inc. (USA). pp 60-66.

Misra, S. K.. and Aspal, P. K.. (2013). A Camel Model Analysis of State Bank Group. World Journal of Social Sciences, 3(4), 36-55.

Olweny, T. and Shipho, T. M. (2011). Effects of banking sectoral factors on the profitability of commercial banks in Kenya. Journal of Economic and Finance, 1(5), 01-30.

Paul K. N. and Yazidu U. (2015). Banks Performance in Ghana: Trends and Determinants. Ghana Journal of Development Studies, 12(1 \& 2):33-52.

Rehana, K. and Irum S. (2012). Gauging the Financial Performance of Banking Sector using CAMEL Model: Comparison of Conventional, Mixed and Pure Islamic Banks in Pakistan. International Research Journal of Finance and Economics. 23(82):67-88.

Siddiqui, M.A., and Shoaib, A. (2011). Measuring performance through capital structure: Evidence from banking sector of Pakistan. African Journal of Business Management. 5(5):18711879.

Vincent O. O. and Gemechu B. K. (2013). Determinants of Financial Performance of Commercial Banks in Kenya. International Journal of Economics and Financial Issues. 3(1):237-252. 